\title{
Hyperplastic thymus with increased angiogenesis is correlated with elevated serum thyroglobulin level in differentiated thyroid cancer patients with TENIS syndrome
}

\author{
Guangjian Zhang ${ }^{1}$, Rui Gao ${ }^{2}$, Yuanbo Wang ${ }^{2}$, Yan Liu², Juan Li $^{2}$, Xi Jia², Yiqian \\ Liang $^{2}$ and Aimin Yang ${ }^{2}$ \\ ${ }^{1}$ Department of Thoracic Surgery, The First Affiliated Hospital of Xi'an Jiaotong University, Xi'an 710061, China \\ ${ }^{2}$ Department of Nuclear Medicine, The First Affiliated Hospital of Xi'an Jiaotong University, Xi'an 710061, China \\ Correspondence to: Aimin Yang, email: jacky_mg@163.com \\ Keywords: differentiated thyroid cancer; TENIS syndrome; integrin $a_{v} \beta_{3^{\prime}}$ thymus; RGD peptide
}

Received: July 11,2017 Accepted: November 17, $2017 \quad$ Published: December 15, 2017

Copyright: Zhang et al. This is an open-access article distributed under the terms of the Creative Commons Attribution License 3.0 (CC BY 3.0), which permits unrestricted use, distribution, and reproduction in any medium, provided the original author and source are credited.

\section{ABSTRACT}

Aims: To investigate the association between angiogenetic activity of hyperplastic thymus and serum thyroglobulin $(\mathrm{Tg})$ level in differentiated thyroid carcinoma patients with thyroglobulin (Tg)-elevated Negative Iodine Scintigraphy (TENIS) Syndrome.

Methods: A cohort of $\mathbf{3 0}$ consecutive patients who underwent total thyroidectomy followed by radioiodine ablation and had TENIS syndrome received integrin $a_{v} \beta_{3}$ targeted imaging with 99mTC-HYNIC-PEG4-E[PEG4-c(RGDfk)]2 (99mTc-3PRGD2). The correlation of angiogenetic activity of the thymus and the serum $\mathrm{Tg}$ levels was evaluated in patients with enlarged thymus.

Results: Enlarged thymus was detected in 9 out of the 30 TENIS patients and all hyperplastic thymus showed an increased accumulation of the tracer (median tumor/background ratio: 2.8). Five of them had only mediastinal uptake and surgical removal of the mediastinal mass in one provided histopathologic evidence of thymic tissue. The other four were not assigned further treatment and were free of disease in the follow-up, though their stimulated $\mathrm{Tg}$ levels consistently increased. Four out of the 9 patients showed $99 \mathrm{~m}$ Tc-3PRGD2 uptake outside the mediastinum were assigned surgery followed by radioiodine treatment. Their stimulated $\mathrm{Tg}$ levels decreased after iodine ablation, but not drop back to normal. A significant linear correlation was observed between serum $\mathrm{Tg}$ levels and the degree of angiogenesis in the hyperplastic thymus.

Conclusions: The angiogenetic activity in hyperplastic thymus was related with the consistently elevated serum Tg levels in TENIS syndrome patients. Based on the existing literature and current data, we propose further intervention for patients with RGD uptake outside thymus, while close follow-up for patients with only mediastinal uptake.

\section{INTRODUCTION}

Differentiated thyroid cancer (DTC) accounts for $1 \%$ of all malignant tumors, and has shown a rapid rise in the past several years [1]. Total thyroidectomy followed by iodine-131 $\left({ }^{131} \mathrm{I}\right)$ ablation is recommended for the initial treatment of DTC patients, with serial serum thyroglobulin (Tg) tests and imaging measurements as follow-up [2].
A situation as there is no radiologically or clinically evident disease, but Tg levels remain detectable or even significantly elevated (TENIS syndrome) is common in clinical practice [3]. The probable explanation for such condition might be that lesion is too small to image but large enough to secret $\mathrm{Tg}$ [4]. Therefore, an empirical ${ }^{131} \mathrm{I}$ ablation or surgery was suggested for TENIS syndrome patients with $\mathrm{Tg}$ level of more than $10 \mu \mathrm{g} / \mathrm{L}$ [5]. However, 
as suggested by recent reports, there is a possibility that the detected $\mathrm{Tg}$ was produced by other benign sources $[6,7]$. Apparently, the recognition of physiological $\mathrm{Tg}$ secretion is critical for patients with the TENIS syndrome to avoid unnecessary treatments.

The ability to concentrate iodide represents a critical step in the production of $\mathrm{Tg}$ [8]. Iodide uptake has been observed in various extra thyroidal tissues in post-surgery DTC patients, including thymus, salivary gland, gastric mucosa, and mammary gland [9]. Some recent studies have identified thymic radioiodine uptake as a frequent cause of a false-positive mediastinal focus on the wholebody ${ }^{131} \mathrm{I}$ scan $\left({ }^{131} \mathrm{I}\right.$ WBS$)$ of post-surgery DTC cases $[10,11]$. As elevated Tg level is frequently observed in DTC patients with thymic hyperplasia, thymus has been suggested as a potential source for physiological $\mathrm{Tg}$ secretion $[12,13]$. It is noteworthy that studies revealed a disappearance of the $\mathrm{Tg}$ elevation after thymus resection in DTC patients who had previously undergone total thyroidectomy and ${ }^{131}$ I therapy [14]. The "thyroid folliclelike" Hassall bodies in the hyperplastic thymus, which could localize iodine, might be responsible for iodine uptake and $\mathrm{Tg}$ secretion in thymus [15].

Thymic endocrine activity was reported to be strongly influenced by neuroendocrine signals, especially thyroid hormones. Thyroid hormones exert their action on the epithelial cells of the thymus deputed to synthesize and secrete thymic peptides [16]. As a result, functional evaluation of the enlarged thymus is essential for understanding its roles in the TENIS syndrome [17]. To our knowledge, no study has investigated the functional changes of hyperplastic thymus in patients with TENIS syndrome. Hence, in this study, we investigated the angiogenetic degree of hyperplastic thymus and analyzed its association with serum Tg level in patients with TENIS syndrome. Technetium 99m ( $\left.{ }^{99 \mathrm{~m}} \mathrm{Tc}\right)$-dimeric cyclic arginine-glycine-aspartic acid (RGD) peptides with three polyethylene glycol spacers ( ${ }^{99 m}$ Tc-3PRGD2) single photon emission computed tomography (SPECT)/X-ray computed tomography (CT) scanning, which has long been adopted in evaluating the angiogenesis in studies through targeting integrin $\alpha_{\mathrm{v}} \beta_{3}$, was used in the present study to measure the angiogenetic activity of hyperplastic thymus.

\section{RESULTS}

All 30 patients with TENIS syndrome had initially received total thyroidectomy and high-dose radioiodine ablation. The median cumulative radioiodine therapy dose was $8.14 \mathrm{GBq}$ (range, 3.7-24.05 GBq). The final diagnostic radioiodine scan was negative along with elevated Tg levels (median stimulated Tg, $108.88 \mathrm{ng} / \mathrm{mL}$; range, $13.5-480 \mathrm{ng} / \mathrm{mL}$ ) and a negative neck US and chest radiography. The demographic and related clinical data of all TENIS syndrome patients are listed in Table 1.
In 9 of 30 patients $(30.0 \%)$, co-registered diagnostic CT scan for ${ }^{99 m}$ Tc-3PRGD2 SPECT/CT revealed an enlarged thymus, a finding that was compatible with the 99mTc-3PRGD2 uptake observed on SPECT/CT images, i.e. all enlarged thymus showed an increased accumulation of the tracer (Figure 1). This group was comprised of seven female and two male papillary thyroid carcinoma patients with a median age of 29 years (range, 19-38 years) (Table 2). Five of the 9 patients with hyperplastic thymus $(55.56 \%)$ showed only mediastinal uptake of ${ }^{99 \mathrm{~m}} \mathrm{Tc}-3 \mathrm{PRGD} 2$ in SPECT/CT, and the remaining 4 patients (44.44\%) also had uptakes outside the mediastinum. These 9 patients were followed up for 11-24 months (median 16 months) after the ${ }^{99 m}$ Tc-3PRGD2 SPECT/CT scan was performed.

The 5 patients who had only mediastinal uptake had serum stimulated $\mathrm{Tg}$ levels ranging from 33.3 to $62.2 \mathrm{ng} / \mathrm{mL}$ before ${ }^{99 \mathrm{~m}} \mathrm{Tc}-3 \mathrm{PRGD} 2 \mathrm{SPECT} / \mathrm{CT}$ scan (Patients 1-5, Table 2). One patient (Patient 1) had serial CT scans showed progressive thymus enlargement (Figure 2); therefore, this patient underwent mediastinal dissection. Histologic examination of resected specimen revealed hyperplastic thymic tissue (Figure 2). The serum Tg level of Patient 1 was significantly decreased after surgery. No any other treatment was carried out between the surgery and the laboratory test, and she was free of disease during a 20-month follow-up (Table 2). In other 4 patients (Patient 2 and 5) with only mediastinal uptake, CT scanning revealed moderately enlarged thymus. Treatment of these 4 patients consisted of inhibition of TSH secretion by levothyroxine (target TSH level, $<0.07 \mathrm{uIU} / \mathrm{mL}$ ) without performing additional surgery or radioiodine treatment. There were no clinical signs of recurrence or metastasis observed during their follow-up; however, their serum stimulated Tg levels were still remarkably elevated by the last follow-up (Table 2).

Four patients who had mediastinal uptake of 3PRGD2 and uptake outside the mediastinum are also presented in Table 2 (Patients 6-9). Their TSH-stimulated Tg levels ranged from 15.5 to $25.1 \mathrm{ng} / \mathrm{mL}$ before ${ }^{99 \mathrm{~m}} \mathrm{Tc}-$ 3PRGD2 SPECT/CT scanning. Treatment of these patients was based on the existence of extra-mediastinal uptake of ${ }^{99 \mathrm{~m} T c-3 P R G D 2}$. In Patient 6-8, whose contrast enhanced CT results confirmed the presence of cervical and mediastinal lymph node metastasis, surgery followed by empirical ${ }^{131} \mathrm{I}$ treatment $(5.55 \mathrm{GBq}, 5.55 \mathrm{GBq}$ and 6.29 GBq, respectively) was performed (Figure 3). Their $\mathrm{Tg}$ levels were decreased after radioiodine treatment; however, the stimulated $\mathrm{Tg}$ levels were still elevated, and even higher at last follow-up in Patient 6 (Table 2). By the end of the study, metastatic lymph node disease was indicated by cervical US in Patient 6, while no signs of recurrence were detected in Patient 7 and 8 . The last patient (Patient 9) showed possible recurrent disease in the thyroid bed on ${ }^{99 m}$ Tc-3PRGD2 SPECT/CT. A dose of 5.55 GBq ${ }^{131} \mathrm{I}$ treatment was carried out in Patient 9, and 
Table 1: Characteristics of the patients with TENIS syndrome $(n=30)$

\begin{tabular}{lc}
\hline Characteristic & Median (range) \\
\hline Age (years) & $42(18-61)$ \\
Gender $(n)$ & 26 \\
Female & 4 \\
Male & 26 \\
Histology $(n)$ & 4 \\
Papillary thyroid carcinoma & $108.88(13.5-480)$ \\
Follicular thyroid carcinoma & $76.78(47.1-100)$ \\
Thyroglobulin (ng/mL) & $3.26(2.53-6.63)$ \\
TSH (uIU/mL) & $0.72(0.1-3.0)$ \\
Tg Ab (ng/mL) & $8.78(0-34)$ \\
Diameter $(\mathrm{cm})^{*}$ & \\
Lymph nodes metastasis ${ }^{\dagger}$ & \\
\hline
\end{tabular}

TSH: thyroid-stimulating hormone; $\mathrm{Tg} \mathrm{Ab}$ : serum thyroglobulin antibody; * the diameter of the primary thyroid tumor; tnumber of lymph nodes dissected in surgery shown by pathology studies as metastatic lesions.
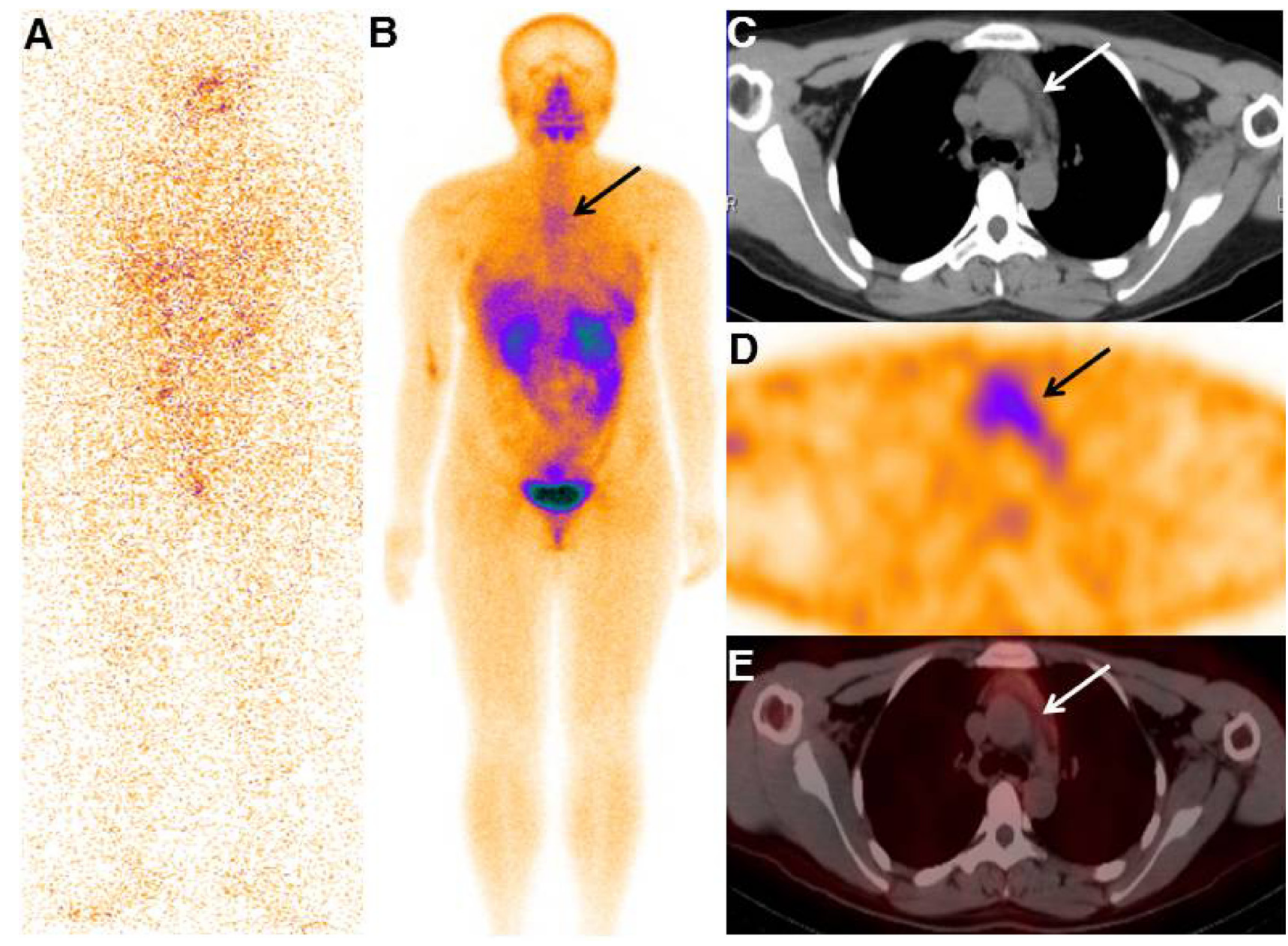

Figure 1: Typical image of the TENIS patient with enlarged thymus that accumulating ${ }^{99 m}$ Tc-3PRGD2. The final diagnostic radioiodine scan was negative (A), while whole-body projection SPECT image showed increased ${ }^{99 \mathrm{~m}}$ Tc-3PRGD2 uptake in the mediastinal region (B, arrow). SPECT/CT images showed increased radiopharmaceutical uptake corresponding to the enlarged thymus in the patient ( $\mathbf{C}-\mathbf{E}$, arrows; from the first to the third row). 
similar to the other 3 patients, stimulated serum Tg level of this patient did not drop back to the expected level $(\leq 2 \mathrm{ng} / \mathrm{mL})$ after radioiodine treatment (Table 2$)$.

The detailed description of the enlarged thymus was presented in Table 3. Most of the enlarged thymus presented as a shape of arrowhead with smooth margins. Because thymic thickness has been shown to be a more consistent indicator of thymic enlargement, we evaluated the relationship of thymic lobe thickness with serum stimulated $\mathrm{Tg}$ levels in these patients. However, no significant correlation was found between thymic lobe thickness and Tg levels. The median T/B ratio of thymus in SPECT/CT images was 2.8 (range 1.8-3.8) in the 9 TENIS syndrome patients with enlarged thymus (Figure 4). It is of note that a significant linear correlation was observed between serum $\mathrm{Tg}$ levels and the $\mathrm{T} / \mathrm{B}$ ratios in patients with only thymus uptake (Pearson $r=0.939, P=0.018$, $n=5$, Figure 5). To tentatively exclude the influence of the metastatic lesions on Tg levels, the post-treatment Tg levels of the 4 patients with metastatic disease, together with Tg levels of 5 patients with only mediastinal uptake, were used to analyze the correlation between serum $\mathrm{Tg}$ levels and the T/B ratios. A positive correlation was still found between the angiogenesis condition of the thymus and the Tg levels in 9 TENIS patients (Pearson $r=0.751$, $P=0.020, n=9$ ).

\section{DISCUSSION}

Elevated $\mathrm{Tg}$ levels coupled with a negative radioiodine scan present problems for the diagnosis and treatment of recurrent DTC [3]. Fluorine-18fluorodeoxyglucose $\left({ }^{18} \mathrm{~F}-\mathrm{FDG}\right)$ positron emission tomography/X-ray computed tomography (PET/CT) is an established imaging modality in cases with TENIS syndrome [18-20]. However, the low probability of obtaining a positive FDG PET result in TENIS patients with sTg levels lower than $30 \mathrm{ng} / \mathrm{mL}$ may hamper its clinical use [19, 20]. Previous studies have focused on the ability of ${ }^{99 \mathrm{~m}}$ Tc-PEG4-E [PEG4-c (RGDfK)]2 (99m Tc3PRGD2) SPECT/CT to specifically image metastatic lymph nodes in DTC patients $[21,22]$. Our study, as far as we know, is the first one focused on its application in evaluating the physiological Tg secretion sources in the follow up of DTC patients. In the present study, 9 out of 30 DTC patients with TENIS syndrome presented upregulated angiogenesis in their enlarged thymus. Surgical removal of the mediastinal mass in 1 patient with progressive thymic hyperplasia provided histopathologic verification of thymic tissue, without any evidence of thyroidal or neoplastic cells. This patient had a significant decrease in the level of Tg after surgery, without any other treatment being performed between the surgery and the
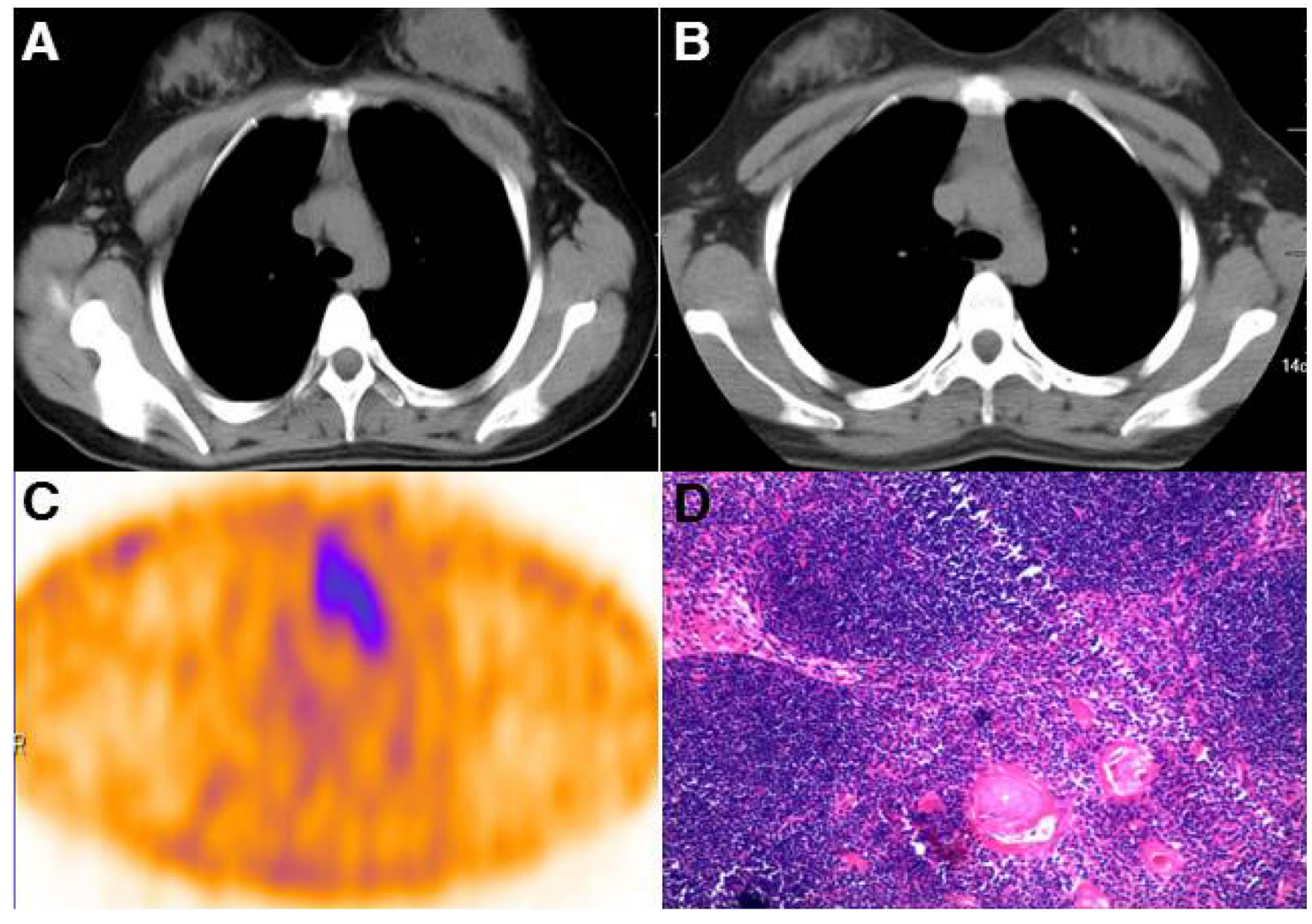

Figure 2: Surgical removal of the mediastinal mass provided histopathologic evidence of thymic tissue. Chest computed tomography showed a large anterior mediastinal mass behind the sternum in Patient 1 (A). The volume of the mass increased gradually (B) and showed increased 3PRGD2 uptake on SPECT/CT scan (C). The pathological examination revealed hyperplastic thymic tissue in the mass (D). 
Table 2: Characteristics of the patients with mediastinum uptake of ${ }^{99 \mathrm{~m}}$ Tc-3PRGD2 $(n=9)$

\begin{tabular}{lccccccccc}
\hline No. & Gender & Age (Yrs) & $\begin{array}{c}\text { Lymph } \\
\text { nodes }^{*}\end{array}$ & $\begin{array}{c}{ }^{131} \mathbf{I} \text { dose } \\
(\mathbf{G B q})^{\dagger}\end{array}$ & $\begin{array}{c}\text { Tg before } \\
(\mathbf{n g} / \mathbf{m L})^{*}\end{array}$ & $\begin{array}{c}\text { Tg last } \\
(\mathbf{n g} / \mathbf{m L})^{\S}\end{array}$ & $\begin{array}{c}\text { RGD } \\
\text { uptake }\end{array}$ & $\begin{array}{c}\text { Follow-up } \\
\text { (months) }\end{array}$ & $\begin{array}{c}\text { Disease } \\
\text { status (5) }\end{array}$ \\
\hline 1 & $\mathrm{~F}$ & 24 & 6 & 11.1 & 62.2 & $18.7 / \mathrm{NT}$ & $\mathrm{L}$ & 20 & $\mathrm{DF}$ \\
2 & $\mathrm{~F}$ & 32 & 16 & 9.25 & 33.3 & $28.3 / \mathrm{NT}$ & $\mathrm{L}$ & 16 & $\mathrm{DF}$ \\
3 & $\mathrm{~F}$ & 28 & 4 & 4.81 & 58.5 & $43.3 / \mathrm{NT}$ & $\mathrm{L}$ & 17 & $\mathrm{DF}$ \\
4 & $\mathrm{M}$ & 29 & 7 & 8.14 & 19.5 & $10.5 / 1.75$ & $\mathrm{~L}$ & 12 & $\mathrm{DF}$ \\
5 & $\mathrm{M}$ & 29 & 19 & 11.1 & 26.1 & $11.2 / \mathrm{NT}$ & $\mathrm{L}$ & 11 & $\mathrm{DF}$ \\
6 & $\mathrm{~F}$ & 19 & 13 & 19.98 & 15.5 & $18.1 / 4.72$ & $\mathrm{M}$ & 18 & $\mathrm{MD}$ \\
7 & $\mathrm{~F}$ & 23 & 5 & 9.25 & 20.3 & $18.3 / \mathrm{NT}$ & $\mathrm{M}$ & 24 & $\mathrm{DF}$ \\
8 & $\mathrm{~F}$ & 43 & 3 & 14.8 & 25.1 & $19.2 / \mathrm{NT}$ & $\mathrm{M}$ & 13 & $\mathrm{DF}$ \\
9 & $\mathrm{~F}$ & 38 & 31 & 10.36 & 18.2 & $14.6 / \mathrm{NT}$ & $\mathrm{M}$ & 14 & $\mathrm{DF}$ \\
\hline
\end{tabular}

F: Female; M: Male; Yrs: years; Tg: serum thyroglobulin; mCi: millicuries; L: limited to mediastinal thymus uptake; M: metastatic to outside uptake; DF: disease free; MD; metastatic disease; Follow-up: duration of follow-up since the performance of ${ }^{99 m}$ Tc-3PRGD2 SPECT/CT; NT: not detectable; ${ }^{*}$ lymph nodes dissected in surgery; ${ }^{\dagger}$ cumulative dose since initiative ${ }^{131} \mathrm{I}$ ablation; "serum TSH stimulated Tg levels before SPECT/CT scan; ${ }^{\S}$ serum stimulated/suppressed Tg levels at last follow-up.

laboratory evaluation. This finding arises the possibility of thymic tissue as a potential source of benign production of $\mathrm{Tg}$ in TENIS syndrome patients. Thymus has been regarded as a benign source of $\mathrm{Tg}$ secretion for a long time. Recent studies have demonstrated the thymic Tg expression in embryonic mice and adult rats [23, 24]. Besides, Sospedra et al. found Tg transcription in 4 of 12 human thymus tissue specimens. Gotter et al. also reported the existence of $\mathrm{Tg}$ expression in medullary epithelial cells of human thymus $[25,26]$.

The other 4 patients with only mediastinal uptake in our study were not assigned further treatment. The CT scans of thymus and periodic monitoring suggested that they are free of disease, i.e., TSH-suppressed Tg $\leq 2 \mathrm{ng} / \mathrm{mL}$ for more than 6 months, though their serum stimulated $\mathrm{Tg}$ levels remained increased in the follow-up. It is of note that the degree of angiogenesis in the hyperplastic thymus in TENIS syndrome patients was closely correlated to the elevated serum Tg levels (Pearson $r=0.939, P=0.018$ ). This relationship supports our hypothesis that the thymus is a benign origin of the elevated $\mathrm{Tg}$ concentrations in TENIS syndrome patients. However, no correlation was found between the volume of the thymus and the $\mathrm{Tg}$ concentrations, which is similar to previous FDG studies [27]. Thus, we concluded that it might be the upregulated angiogenesis, not hyperplasia in thymus that affect the secretion of Tg in the enlarged thymus.

Four of the 9 patients with TENIS syndrome had ${ }^{99 m}$ Tc-3PRGD2 uptake inside and outside the thymus, and received lymphadenectomy followed by radio-iodine treatment. The serum levels of Tg in these 4 patients were decreased after iodine ablation, but the levels did not drop below the expected threshold. Their stimulated Tg levels remained moderately elevated in the follow-up. Based on previous reports and our data, it could be hypothesized that the activated thymus kept on hypersecreting hormones, including $\mathrm{Tg}$, in the patients during follow-up. The upregulated angiogenesis in thymus provides adequate blood supply to maintain its hypersecretion [28-30]. Actually, a positive correlation was still found between
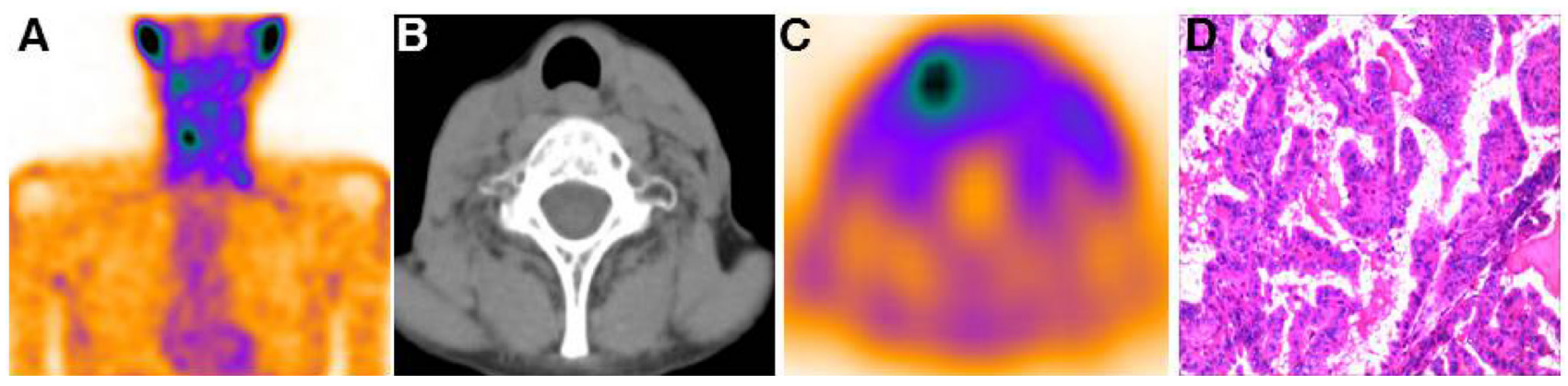

Figure 3: ${ }^{99 m}$ Tc-3PRGD2 uptake outside the thymus was documented cervical lymph nodes metastasis. The ${ }^{99 m}$ Tc3PRGD2 planetary images of Patient 7 showed increased uptake of the tracer outside mediastinal region (A). The SPECT/CT images demonstrated increased radiopharmaceutical uptake corresponding to the cervical lymph nodes (B and $\mathbf{C})$. The patient underwent cervical lymph node dissection and histopathology results documented metastasis disease from DTC $(\mathbf{C})$. 
Table 3: Characteristics of the enlarged thymus $(n=9)$

\begin{tabular}{|c|c|c|c|c|c|c|}
\hline \multirow{2}{*}{ No. } & \multicolumn{3}{|c|}{ Volume dimensions (mm) } & \multirow{2}{*}{ Shape } & \multirow{2}{*}{ Margins } & \multirow{2}{*}{ Internal characteristics } \\
\hline & thickness & transverse & craniocaudal & & & \\
\hline 1 & 25.3 & 30.1 & 25.1 & quadrilateral & smooth & homogeneous \\
\hline 2 & 15.9 & 57.6 & 36.8 & arrowhead & smooth & inhomogeneous \\
\hline 3 & 14.8 & 32.4 & 23.5 & arrowhead & multi-lobular & inhomogeneous \\
\hline 4 & 15.4 & 51.8 & 40.0 & arrowhead & smooth & homogeneous \\
\hline 5 & 14.0 & 31.2 & 17.7 & arrowhead & smooth & homogeneous \\
\hline 6 & 15.0 & 18.2 & 15.9 & arrowhead & smooth & inhomogeneous \\
\hline 7 & 15.4 & 59.4 & 35.3 & arrowhead & smooth & homogeneous \\
\hline 8 & 13.2 & 23.9 & 16.9 & rounded & multi-lobular & inhomogeneous \\
\hline 9 & 15.6 & 16.6 & 15.4 & quadrilateral & smooth & inhomogeneous \\
\hline
\end{tabular}

the angiogenesis condition of thymus and the $\mathrm{Tg}$ levels in the 9 TENIS syndrome patients when the contribution of the metastatic lesions in 4 patients with lymph node metastasis was tentatively excluded (Pearson $r=0.751$, $P=0.020, n=9)$.

The incidence of thymus visualization on ${ }^{131} \mathrm{I}$ scintigraphy has been estimated to be between 3.4 and $26.3 \%$ in different series [5, 31, 32-35]. It has been indicated that the acquired "thyroid follicle-like" structure that exists in the thymus of DTC patients after iodine treatment might be responsible for thymic epithelial cell iodine uptake $[5,32]$. As reported in some studies, thymic iodine uptake was much more commonly observed in the subgroup of DTC patients without Tg elevation, and the elevated Tg level in DTC patients who showed only mediastinal uptake on iodine WBS was decreased to normal range after iodine treatment [33, 34, 36]. It is noteworthy that the patients with increased $\mathrm{Tg}$ in our study demonstrated a negative radioiodine uptake on ${ }^{131}$ I WBS, even though the increased angiogenesis was determined in their hyperplastic thymus tissue by the ${ }^{99}$ Tc-3PRGD2 SPECT/CT. Moreover, as we mentioned above, their stimulated $\mathrm{Tg}$ levels did not drop back to lower than $2 \mathrm{ng} / \mathrm{mL}$ after radio-iodine treatment. Therefore, it could be concluded that the hyperplastic thymus in the patients with TENIS syndrome may not be as differentiated as the thymic tissues seen on the ${ }^{131} \mathrm{I}$ WBS, which is considered to possess the property

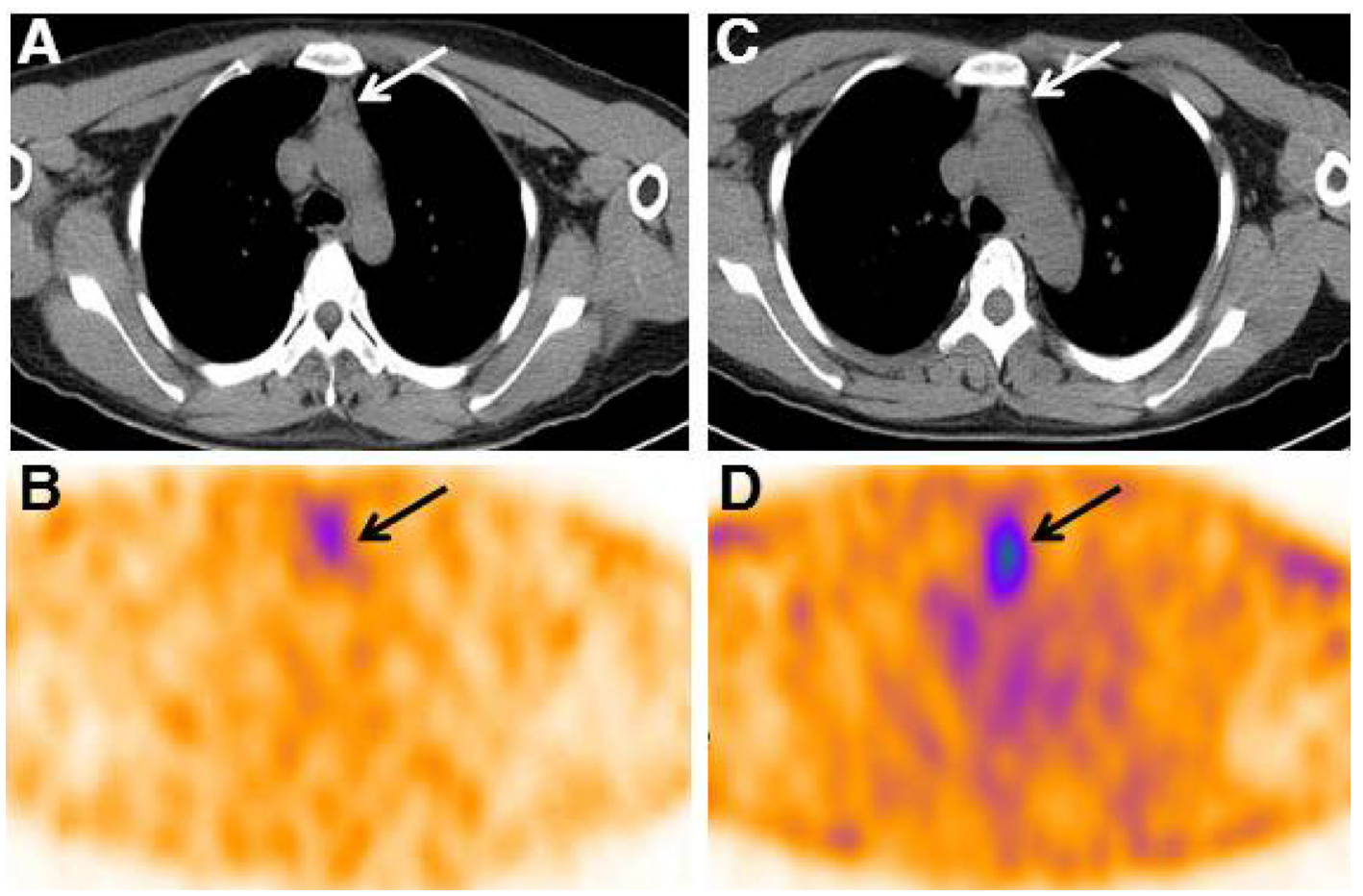

Figure 4: Two representative ${ }^{99 \mathrm{~m}}$ Tc-3PRGD2 SPECT/CT images of TENIS patients with different serum Tg levels. (A-B) Patient 9 with stimulated Tg of $18.2 \mathrm{ng} / \mathrm{mL}$ demonstrated a uptake ratio of 1.8 in thymus; (C-D), Patient 3 with stimulated Tg of $58.5 \mathrm{ng} / \mathrm{mL}$ showed a $\mathrm{T} / \mathrm{B}$ ratio of 3.2 in thymus. 
of uptaking iodine [35]. This kind of de-differentiated thymus tissue might keep on producing $\mathrm{Tg}$, or Tg like secretions in the DTC patients [37].

Our results, for the first time, indicated that there is an increased prevalence of angiogenesis in thymic hyperplasia of the patients with DTC. We also found that the degree of angiogenesis in the hyperplastic thymus was positively correlated with the elevated serum $\mathrm{Tg}$ level. The Tg levels would not fall back to normal even after an ablative radioiodine therapy dose had been administered. The understanding of the ${ }^{99 \mathrm{~m} T c-3 P R G D 2}$ imaging appearance of thymic hyperplasia and its association with increased serum $\mathrm{Tg}$ level is important for preventing misdiagnosis of metastatic disease and avoiding unnecessary treatment, such as surgery or radioiodine therapy $[38,39]$. Further longitudinal studies are needed to confirm that the hyperplastic thymic with activated angiogenesis does not necessarily herald recurrence and metastasis of DTC [40].

This study is limited by a selection bias in that only a small number of TENIS syndrome patients were included and were only followed for a limited period. Thus, it may not be possible to generalize our results to all DTC patients. To further clarify this issue, we are beginning a prospective, longitudinal study that will include DTC patients after radioiodine ablation at our institution, thus avoiding the selection bias.
In summary, our study indicated that thymic hyperplasia was commonly observed in thyroid cancer patients, and the hyperplastic thymus with activated vasculature was strongly related with consistently elevated Tg levels in the follow-up of our patients. Based on the existing literature and our data, we propose further intervention for patients with outside thymus uptake of RGD, while close follow-up for patients with only mediastinal uptake.

\section{MATERIALS AND METHODS}

\section{Subjects}

Between January 2015 and December 2016, 763 DTC patients were referred to the Department of Nuclear Medicine at The First Affiliated Hospital of Xi'an Jiaotong University for adjuvant radioiodine treatment after total thyroidectomy. Then they were followed up with serial Tg tests and imaging measurements including neck ultrasound (US), CT scans, and diagnostic dosage ${ }^{131} \mathrm{I}$ WBS $[1,2]$. Among these patients, 30 cases presented with increased $\mathrm{Tg}(>2 \mathrm{ng} / \mathrm{mL})$ on thyroid-stimulating hormone (TSH) stimulation and negative results in radiological tests in the follow-up enrolled in for a ${ }^{99 \mathrm{~m} T c-3 P R G D 2 ~ S P E C T / C T ~[41] . ~}$

${ }^{131}$ I WBS was obtained with a large field gamma camera, whole body and high energy collimator, $48 \mathrm{~h}$ after

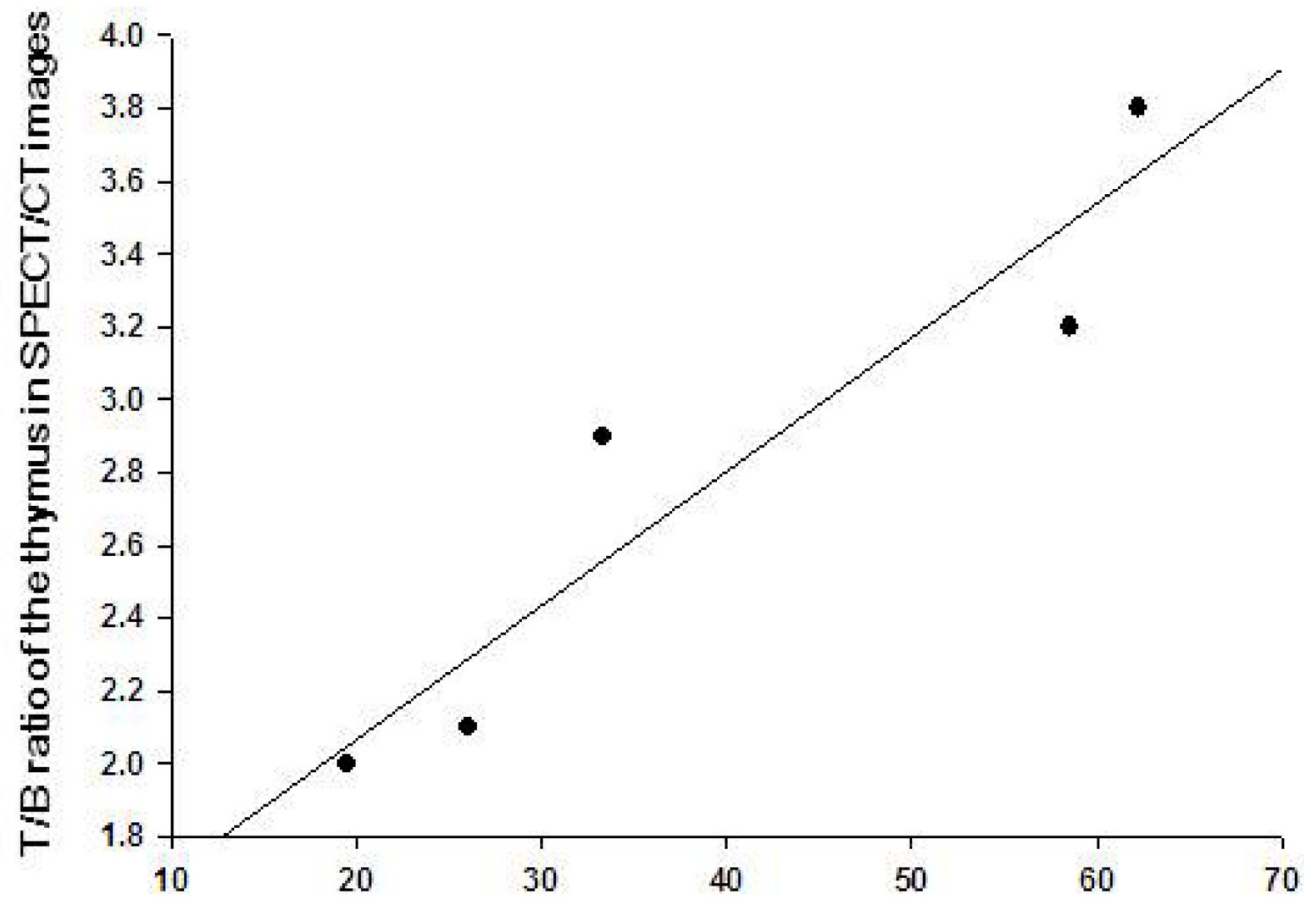

\section{Stimulated Tg levels in cases with mediastinal uptake only $(n=5)$}

Figure 5: The correlation of the TSH-stimulated serum Tg levels and the angiogenesis activity of the hyperplastic thymus in cases with mediastinal uptake only. Typical linear plots indicated that the TSH-stimulated serum Tg levels were significantly correlated with the Tumor/Background ratios of the enlarged thymus on ${ }^{99 \mathrm{~m}} \mathrm{Tc}-3 \mathrm{PRGD} 2 \mathrm{SPECT} / \mathrm{CT}(n=5)$. 
the administration of oral diagnostic dose of $185 \mathrm{MBq}{ }^{131} \mathrm{I}$ to each patient. CT scans were performed using a 64-channel CT scanner [Philips (China) Investment Co., Ltd.], and all scans were performed from the cervix to thorax. Serum $\mathrm{TSH}, \mathrm{Tg}$, and anti-Tg antibody levels were measured by radioimmunoassay (GASK-PR, CIS-Bio International, subsidiary of Schering S.A., Gif-sur-Yvette, France).

None of the patients had circulating anti-Tg antibodies detected in this study. All the subjects signed informed consent documents. The protocol for this study was in accordance with the Declaration of Helsinki and its subsequent revisions, and it was approved by the Institutional Review Boards of the First Affiliated Hospital of Xi'an Jiaotong University.

\section{9mTc-3PRGD2 SPECT/CT imaging}

As mentioned, 30 DTC cases with TENIS syndrome were enrolled in for a ${ }^{99 m}$ Tc-3PRGD2 SPECT/CT. Synthesis of the labeling precursor, kit preparation and subsequent ${ }^{99 \mathrm{~m}} \mathrm{Tc}$-labeling were performed as previously described [21]. ${ }^{99 \mathrm{~m}} \mathrm{Tc}-3 \mathrm{PRGD} 2 \mathrm{SPECT}$ and coregistered $\mathrm{CT}$ were performed $0.5 \mathrm{~h}$ after intravenous injection of 11.1 MBq/kg (0.3 mCi/kg) of ${ }^{99 m}$ Tc-3PRGD2. The Dicom image files of each patient were saved in optic discs and transferred to a Symbia T16 workstation (Siemens, Germany) for analysis.

${ }^{99 m}$ Tc-3PRGD2 SPECT images were visually interpreted by the consensus of three experienced nuclear medicine physicians with reference to SPECT/CT fusion and CT images. For each case, the mediastinum was reviewed on soft-tissue window settings in the co- registered diagnostic $\mathrm{CT}$ (window level $=50$, window width $=350$ ). For cases that met criteria for thymic hyperplasia, medical imaging records were reviewed [36]. Measurements of the size (craniocaudal extent, maximum transverse dimensions and thickness, Figure 6), shape (triangular, arrowhead, round, or quadrilateral), margin (smooth or multi-lobular), and internal characteristics of structures (homogeneous or inhomogeneous because of fatty infiltrations) of the thymus were analyzed using an electronic caliper measuring device available on our PACS software [31, 42]. The ${ }^{99 \mathrm{~m}}$ Tc-3PRGD2 uptake in the thymus was also analyzed. For semi-quantitative analysis, tumor-to-background (T/B) ratios of the SPECT/ CT images were measured by the same physicians using a standardized method as described below. A volume-ofinterest method was used to obtain the maximum values of the enlarged thymus in mediastinal region. The blood pool of the aortic arch was set as control [43].

\section{Follow-up}

The SPECT/CT findings were compared with histopathological findings, serial radiological or clinical follow-up [43]. In patients with only stable thymus enlargement on concomitant imaging, no therapeutic intervention was initiated, whereas patients with other metastatic lesions received surgery and/or an empirical ${ }^{131}$ I treatment. Mediastinal dissection was carried out in patients showing progressive thymus enlargement. Patients were considered free of disease if there were no clinical or biochemical signs of recurrence, i.e., $\mathrm{Tg} \leq 2 \mathrm{ng} / \mathrm{mL}$ accompanied by negative diagnostic ${ }^{131}$ I WBS under 3-4

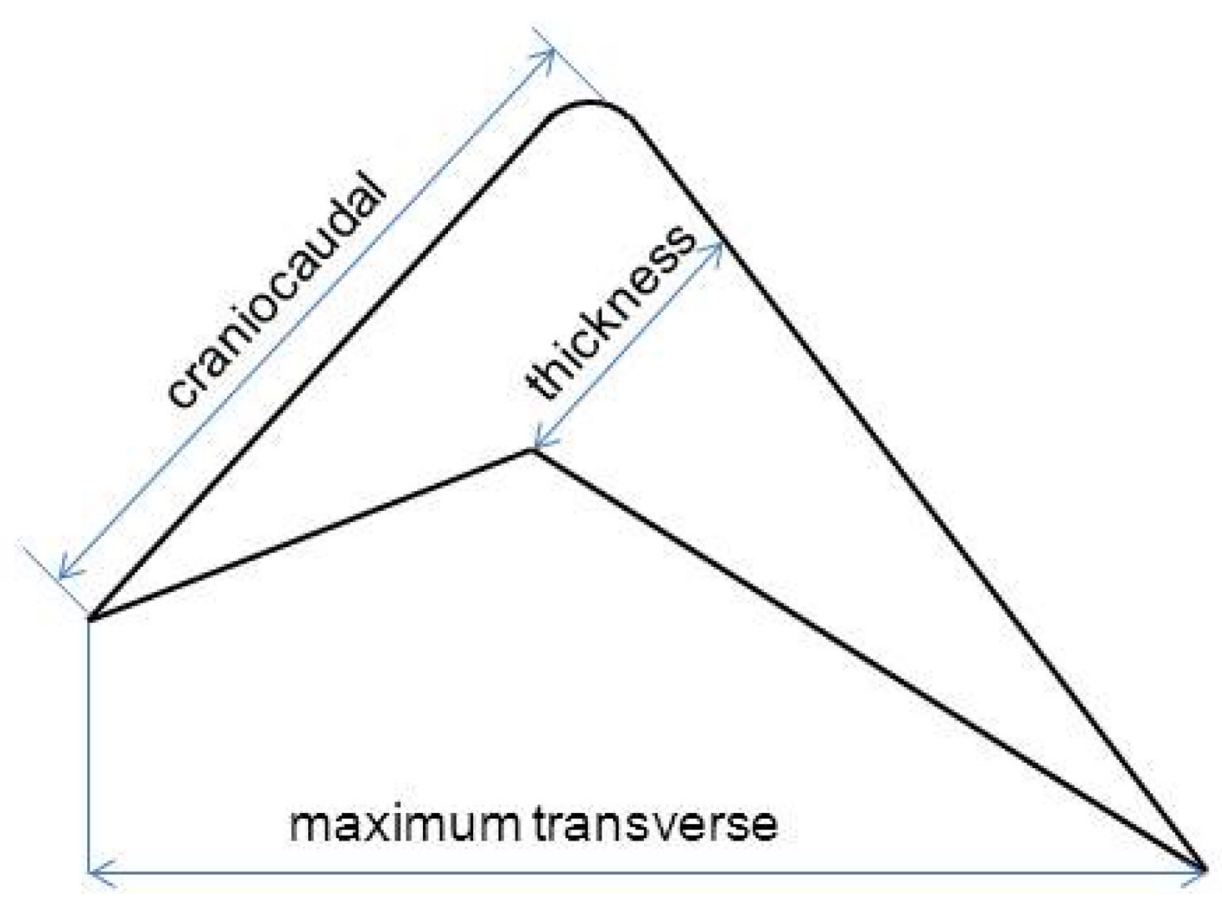

Figure 6: Measurement method of the thickness, craniocaudal and maximum transverse dimensions of the thymus gland. 
weeks TSH stimulation, or $\mathrm{Tg} \leq 2 \mathrm{ng} / \mathrm{mL}$ for at least 6 months (evaluated every 3 months) under thyroid hormone suppression therapy [5].

\section{Statistical analysis}

Data are shown as the mean \pm SD or median (range), as appropriate. To identify individual patients in the current study, we assigned each patient a unique number, which is used throughout the text, tables, and figures. Pearson correlation analysis was performed to assess the linear relation between $\mathrm{T} / \mathrm{B}$ ratios and the serum $\mathrm{Tg}$ levels. A $P$-value of less than 0.05 was considered statistically significant.

\section{Abbreviations}

Tg-elevated Negative Iodine Scintigraphy: TENIS, Tumor/Background: T/B, Thyroglobulin: Tg, Differentiated thyroid cancer: DTC, ${ }^{131}$ I Whole-body scan: ${ }^{131}$ I WBS, Single photon emission computed tomography/ X-ray computed tomography: SPECT/CT, Thyroidstimulating hormone: TSH, Tumor-to-background: T/B.

\section{Author contributions}

conceptualization: GJZ AMY. Data curation: RG. Formal analysis: GJZ RG. Investigation: YBW YL JL XJ XNL. Methodology: AMY. Project administration: GJZ. Supervision: AMY. Writing-original draft: GJZ RG. Writing-review\& editing: YQL AMY.

\section{ACKNOWLEDGMENTS}

The authors would like to thank Yan Yu, Professor of Epidemiology from Medical Institute of Xi'an Jiaotong University, for assistance in statistical analysis. The authors also want to give their thanks to Dr. Jianjun Xue, Huixing Deng, Geng Qianqian, and other related staff from the Department of Nuclear Medicine for their help in the study performance and data collection.

\section{CONFLICTS OF INTEREST}

The authors declare that they have no conflicts of interest.

\section{REFERENCES}

1. Lubitz CC, Sosa JA. The changing landscape of papillary thyroid cancer: Epidemiology, management, and the implications for patients. Cancer. 2016; 122:3754-3759. https://doi.org/10.1002/cncr.30201.

2. Cooper DS, Doherty GM, Haugen BR, Kloos RT, Lee SL, Mandel SJ, Mazzaferri EL, McIver B, Pacini F,
Schlumberger M, Sherman SI, Steward DL, Tuttle RM, and American Thyroid Association (ATA) Guidelines Taskforce on Thyroid Nodules and Differentiated Thyroid Cancer. Revised American Thyroid Association management guidelines for patients with thyroid nodules and differentiated thyroid cancer. Thyroid. 2009; 19:1167214. https://doi.org/10.1089/thy.2009.0110.

3. Silberstein EB. The problem of the patient with thyroglobulin elevation but negative iodine scintigraphy: the TENIS syndrome. Semin Nucl Med. 2011; 41:113-120. https://doi.org/10.1053/j.semnuclmed.2010.10.002.

4. Papageorgiou M, Liratzopoulos N, Minopoulos G, Manolas K. Thyroglobulin-what is the postoperative threshold for the suspicion of thyroid cancer recurrence in the absence of anti-Tg antibody measurement? South African Journal of Surgery. 2011; 49:118-122.

5. Haveman JW, Phan HT, Links TP, Jager PL, Plukker J. Implications of mediastinal uptake of ${ }^{131} \mathrm{I}$ with regard to surgery in patients with differentiated thyroid carcinoma. Cancer. 2005; 103:59-67. https://doi.org/10.1002/ cncr.20725.

6. Bestagno M, Pagliaini R, Maira G, Pizzoearo C. Mediastinal uptake of 131-I in patients with thyroid cancer: may it be referred to normal thymus? Eur J Nucl Med. 1993; 20:648-648.

7. Haghighatafshar M, Farhoudi F. Incidentally visualization of the thymus on whole-body iodine scintigraphy: Report of 2 cases and review of the latest insights. Medicine. 2015; 94:e1015. https://doi.org/10.1097/MD.0000000000001015.

8. Wartofsky L, Van Nostrand D. Radioiodine treatment of well-differentiated thyroid cancer. Endocrine. 2012; 42:506-13. https://doi.org/10.1007/s12020-012-9729-5.

9. Spitzweg C, Joba W, Eisenmenger W, Heufelder A. Analysis of human sodium iodide symporter gene expression in extrathyroidal tissues and cloning of its complementary deoxyribonucleic acids from salivary gland, mammary gland, and gastric mucosa. J Clin Endocrinol Metab. 1998; 83:1746-1751. https://doi.org/10.1210/jcem.83.5.4839.

10. Davidson J, McDougall IR. How frequently is the thymus seen on whole-body iodine-131 diagnostic and posttreatment scans? : Eur J Nucl Med. 2000; 27:425-430.

11. Michigishi T, Mizukami Y, Shuke N, Yokoyama K, Noguchi M, Watanabe Y, Matsui O, Aburano T, Tonami N, Hisada $\mathrm{K}$. Visualization of the thymus with therapeutic doses of radioiodine in patients with thyroid cancer. Eur J Nucl Med. 1993; 20:75-79.

12. Muratet J, Giraud P. Thymus accumulation of I-131 after therapeutic dose for thyroid carcinoma. Clin Nucl Med. 1996; 21:736-737.

13. Zanotti-Fregonara $\mathrm{P}$, Keller I, Calzada-Nocaudie $\mathrm{M}$, Al-Nahhas A, Devaux JY, Grassetto G, Marzola MC, Rubello D, Hindié E. Increased serum thyroglobulin levels and negative imaging in thyroid cancer patients: are there sources of benign secretion? Nucl Med 
Commun. 2010; 31:1054-1058. https://doi.org/10.1097/ MNM.0b013e328340e717.

14. Veronikis IE, Simkin P, Braverman LE. Thymic uptake of iodine-131 in the anterior mediastinum. J Nucl Med. 1996; 37:991-992.

15. Vermiglio F, Baudin E, Travagli JP, Caillou B, Fragu P, Ricard M, Schlumberger M. Iodine concentration by the thymus in thyroid carcinoma. J Nucl Med. 1996; 37:1830-1831.

16. Fabris N, Mocchegiani E, Mariotti S, Pacini F, Pinchera A. Thyroid-thymus interactions during development and aging. Horm Res. 1989; 31:85-89.

17. Wilson LM, Barrington SF, Morrison ID, Kettle AG, O'Doherty MJ, Coakley AJ. Therapeutic implications of thymic uptake of radioiodine in thyroid carcinoma. Eur $\mathrm{J}$ Nucl Med. 1998; 25:622-28.

18. Dong MJ, Liu ZF, Zhao K, Ruan LX, Wang GL, Yang SY, Sun F, Luo XG. Value of ${ }^{18}$ F-FDG-PET/PET-CT in differentiated thyroid carcinoma with radioiodinenegative whole-body scan: a meta-analysis. Nucl Med Commun. 2009; 30:639-650. https://doi.org/10.1097/ MNM.0b013e32832dcfa7.

19. Choi SJ, Jung KP, Lee SS, Park YS, Lee SM, Bae SK. Clinical Usefulness of F-18 FDG PET/CT in Papillary Thyroid Cancer with Negative Radioiodine Scan and Elevated Thyroglobulin Level or Positive Antithyroglobulin Antibody. Nucl Med Mol Imaging. 2016; 50:130-136. https://doi.org/10.1007/s13139-015-0378-5.

20. Vural GU, Akkas BE, Ercakmak N, Basu S, Alavi A. Prognostic significance of FDG PET/CT on the follow-up of patients of differentiated thyroid carcinoma with negative ${ }^{131}$ I whole-body scan and elevated thyroglobulin levels: correlation with clinical and histopathologic characteristics and long-term follow-up data. Clin Nucl Med. 2012; 37:953-959. https://doi.org/10.1097/ RLU.0b013e31825b2057.

21. Jin X, Liang N, Wang M, Meng Y, Jia B, Shi X, Li S, Luo J, Luo Y, Cui Q, Zheng K, Liu Z, Shi J, et al. Integrin Imaging with 99mTc-3PRGD2 SPECT/CT Shows High Specificity in the Diagnosis of Lymph Node Metastasis from NonSmall Cell Lung Cancer. Radiology. 2016; 281:958-966. https://doi.org/10.1148/radiol.2016150813.

22. Zhao D, Jin $X$, Li F, Liang J, Lin Y. Integrin $\alpha_{v} \beta_{3}$ imaging of radioactive iodine-refractory thyroid cancer using ${ }^{99 \mathrm{~m}} \mathrm{Tc}$ 3PRGD2. J Nucl Med. 2012; 53:1872-1877.

23. Heath VL, Moore NC, Parnell SM, Mason DW. Intrathymic expression of genes involved in organ specific autoimmune disease. J Autoimmun. 1998; 11:309-318. https://doi. org/10.1006/jaut.1998.0210.

24. Mello ME, Flamini RC, Corbo R, Mamede M. Radioiodine concentration by the thymus in differentiated thyroid carcinoma: report of five cases. Arq Bras Endocrinol Metabol. 2009; 53:874-879.
25. Gotter J, Brors B, Hergenhahn M, Kyewski B. Medullary epithelial cells of the human thymus express a highly diverse selection of tissue-specific genes colocalized in chromosomal clusters. J Exp Med. 2004; 199:155-166. https://doi.org/10.1084/jem.20031677.

26. Sospedra M, Ferrer-Francesch X, Domínguez O, Juan M, Foz-Sala M, Pujol-Borrell R. Transcription of a broad range of self-antigens in human thymus suggests a role for central mechanisms in tolerance toward peripheral antigens. J Immunol. 1998; 161:5918-5929.

27. Jeon TJ, Lee YS, Lee JH, Chang HS, Ryu YH. Rebound thymic hyperplasia detected by ${ }^{18} \mathrm{~F}$-FDG PET/CT after radioactive iodine ablation therapy for thyroid cancer. Thyroid. 2014; 24:1636-1641. https://doi.org/10.1089/ thy.2014.0164.

28. Cuddihy AR, Suterwala BT, Ge S, Kohn LA, Jang J, Andrade J, Wang X, Crooks GM. Rapid thymic reconstitution following bone marrow transplantation in neonatal mice is VEGF-dependent. Biol Blood Marrow Transplant. 2012; 18:683-689. https://doi.org/10.1016/j. bbmt.2012.01.006.

29. Park HJ, Kim MN, Kim JG, Bae YH, Bae MK, Wee HJ, Kim TW, Kim BS, Kim JB, Bae SK, Yoon S. Up-regulation of VEGF expression by NGF that enhances reparative angiogenesis during thymic regeneration in adult rat. Biochim Biophys Acta. 2007; 1773:1462-1472. https://doi. org/10.1016/j.bbamcr.2007.05.006.

30. Raica M, Mogoanta L, Kondylis A, Cimpean AM. Angiogenesis in the human thymoma assessed by subclassification of tumorassociated blood vessels and endothelial cells proliferation. Rom J Morphol Embryol. 2010; 51:627-631.

31. Niendorf ER, Parker JA, Yechoor V, Garber JR, Boiselle PM. Thymic hyperplasia in thyroid cancer patients. J Thorac Imaging. 2005; 20:1-4.

32. Meller J, Becker W. The human sodium-iodine symporter (NIS) as a key for specific thymic iodine-131 uptake. Eur J Nucl Med. 2000; 27:473-474.

33. Arce MB, Molina TC, Hernández TM, de la Cinta Calvo Morón M, Herrero CH, De La Riva Pérez PA, Montaño JC. Thymic uptake after high-dose I-131 treatment in patients with differentiated thyroid carcinoma: A brief review of possible causes and management. Endocrinol Nutr. 2015; 62:19-23. https://doi.org/10.1016/j.endonu.2014.06.005.

34. Nakamura T, Murakami M, Horiguchi H, Nagasaka S, Ishibashi $\mathrm{S}$, Mori M, Ishikawa SE. A case of thymic enlargement in hyperthyroidism in a young woman. Thyroid. 2004; 14 : 307-310. https://doi.org/10.1089/105072504323030979.

35. Kakudo K, Bai Y, Ozaki T, Homma KI, Ito Y, Miyauchi A. Intrathyroid epithelial thymoma (ITET) and carcinoma showing thymus-like differentiation (CASTLE): CD5positive neoplasms mimicking squamous cell carcinoma of the thyroid. Histol Histopathol. 2013; 28:543-556. https:// doi.org/10.14670/HH-28.543. 
36. Nicolaou S, Müller NL, Li DK, Oger JJ. Thymus in myasthenia gravis: comparison of $\mathrm{CT}$ and pathologic findings and clinical outcome after thymectomy. Radiology. 1996; 201:471-474. https://doi.org/10.1148/radiology.201.2.8888243.

37. Li B, Li J, Hsieh CS, Hale LP, Li YJ, Devlin BH, Markert ML. Characterization of cultured thymus tissue used for transplantation with emphasis on promiscuous expression of thyroid tissue-specific genes. Immunol Res. 2009; 44:71-83. https://doi.org/10.1007/s12026-008-8083-4.

38. Basu S, Dandekar M, Joshi A, D’Cruz A. Defining a rational step-care algorithm for managing thyroid carcinoma patients with elevated thyroglobulin and negative on radioiodine scintigraphy (TENIS): considerations and challenges towards developing an appropriate roadmap. Eur J Nucl Med Mol Imaging. 2015; 42:1167-1171. https://doi. org/10.1007/s00259-015-3058-x.

39. Mousa U, Yilmaz A, Nar A. Stimulated thyroglobulin values above $5.6 \mathrm{ng} / \mathrm{ml}$ before radioactive iodine ablation treatment following levothyroxine withdrawal is associated with a 2.38-fold risk of relapse in Tg-ab negative subjects with differentiated thyroid cancer. Clin Transl Oncol. 2017; 19:1028-1034. https://doi.org/10.1007/s12094-017-1640-3.
40. Godart V, Weynand B, Coche E, De Nayer P, Daumerie C. Intense 18-fluorodeoxyglucose uptake by the thymus on PET scan does not necessarily herald recurrence of thyroid carcinoma. J Endocrinol Invest. 2005; 28:1024-1028.

41. Bannas P, Derlin T, Groth M, Apostolova I, Adam G, Mester J, Klutmann S. Can (18)F-FDG-PET/CT be generally recommended in patients with differentiated thyroid carcinoma and elevated thyroglobulin levels but negative I-131 whole body scan? Ann Nucl Med. 2012; 26:77-85. https://doi.org/10.1007/s12149-011-0545-4.

42. Francis IR, Glazer GM, Bookstein FL, Gross BH. The thymus: reexamination of age-related changes in size and shape. AJR Am J Roentgenol. 1985; 145:249-254. https:// doi.org/10.2214/ajr.145.2.249.

43. Gao R, Zhang G, Chen L, Zhu Z, Wang F, Yang A. Utility of 99mTc-PEG4-E [PEG4-c (RGDfK)] 2 in Posttherapy Surveillance of Patients with Reelevated Carcinoembryonic Antigen Levels. Med Princ Pract. 2015; 24:244-249. https:// doi.org/10.1159/000381287. 